\author{
Cristina Granziera \\ Patrik Michel \\ Andrea O. Rossetti \\ Floriana Lurati \\ Sitthided Reymond \\ Julien Bogousslavsky
}

\section{Wegener Granulomatosis presenting with haemorragic stroke in a young adult}

Received: 7 May 2004

Received in revised form: 8 October 2004

Accepted: 19 October 2004

Published online: 22 March 2005

Sirs: Haemorrhagic stroke in young patients is primarily caused by elevated blood pressure, underlying vascular structural abnormalities, cardiac embolism or migraine [1-3]. Vasculitis may be a possible but uncommon aetiology of ischemic stroke in patients aged less than 45 years [4] and rarely causes brain haemorrhage $[5,6]$. We report on a patient who presented with haemorrhagic stroke as the initial symptom of Wegener granulomatosis (WG).

In March 2003, a 42 year old male smoker presented with acute onset of a right sensorimotor hemisyndrome accompanied by motor aphasia. Magnetic resonance imaging (MRI) revealed a haemorrhagic stroke in the left basal ganglia, without underlying ischaemic damage (Figure). No vascular malformation, aneurysm, tumour or venous thrombosis was observed. Acutely, blood pressure was $180 / 90 \mathrm{mmHg}$ but funduscopy as well as urinary sediment did not show signs of chronic hypertensive damage. Cerebrovascular Doppler ultrasound and transthoracic echocardiography were negative. Laboratory investigations showed mild inflammatory signs and im-
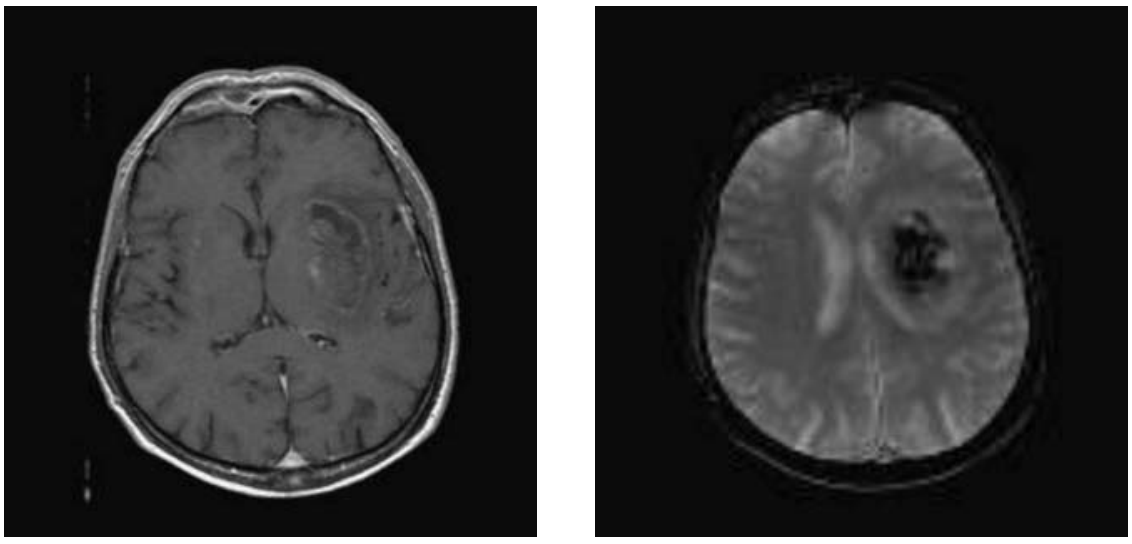

Fig. T1 (left) and FLAIR (right) weighted brain MRI show predominantly hypointense lesion in the left lenticular nucleus (left) with a hyperintense oedematous ring surrounding the lesion (right)

munological tests revealed elevated c-ANCA and anti PR-3 antibodies (Table); p-ANCA, $\mathrm{x}$-ANCA, anti MPO antibodies, as well as CSF analysis were negative. The patient had no symptoms or signs characteristic of WG: renal function, urinary sediment, thorax radiography and otorhinolaryngological examination were normal. Three months later, the patient had no symptoms, normal inflammatory parameters and still elevated autoantibodies (Table). In November 2003, he developed acute respiratory distress, fever, oral ulcers, epistaxis and arthralgia. Lung CT showed subpleural nodules and infiltrates and bronchoscopic bronchoalveolar lavage revealed intraalveolar haemorrhage (30\% haemosidero-

phages). Microbiological analysis for pneumocystis, nocardia, mycoses, mycobacteries and CMV was negative. Tongue and gingival biopsy specimens showed non specific ulcers. Glomerular microhaematuria (95 RBC/field) and mild proteinuria $(0.3 \mathrm{~g} / \mathrm{l}$ proteins) were now observed. Renal biopsy revealed an impaired immunity crescentic extracapillary glomerulonephritis without granulomatous lesions; c-ANCA and anti PR-3 antibodies elevation persisted and inflammatory parameters had reappeared (Table). Three out of four ACR classification criteria [7] were positive, so the diagnosis of WG was established. The patient was treated with intravenous steroids and cyclophosphamide. One month later, inflammatory signs as well as autoantibodies normalised and all systemic signs and symptoms had resolved completely.

This patient presented with haemorrhagic stroke; he did not

Table Comparative evolution of autoantibodies levels, inflammatory parameters, and clinical features

\begin{tabular}{lllll}
\hline & March 2003 & July 2003 & November 2003 & December 2003 \\
\hline Anti c-ANCA (n. r. $<1 / 20)$ & $1 / 320^{*}$ & $1 / 320^{*}$ & $1 / 320^{*}$ & - \\
Anti PR3 $($ n. r. $<20 \mathrm{U})$ & $73 \mathrm{U}^{*}$ & $67 \mathrm{U}^{*}$ & $75 \mathrm{U}^{*}$ & $21 \mathrm{U}$ \\
ESR $($ n. r. $<10 \mathrm{~mm} / \mathrm{h})$ & $33 \mathrm{~mm} / \mathrm{h}^{*}$ & $10 \mathrm{~mm} / \mathrm{h}$ & $40 \mathrm{~mm} / \mathrm{h}^{*}$ & $18 \mathrm{~mm} / \mathrm{h}$ \\
CRP (n. r. $<10 \mathrm{mg} / \mathrm{l})$ & $31 \mathrm{mg} / \mathrm{l}^{*}$ & $<2 \mathrm{mg} / \mathrm{l}$ & $70 \mathrm{mg} / \mathrm{l}^{*}$ & \\
Symptoms & $\begin{array}{l}\text { Haemorrhagic } \\
\text { stroke }\end{array}$ & None & $\begin{array}{l}\text { Fever, arthralgia, ENT, } \\
\text { lung, kidney disease }\end{array}$ & None \\
& & & & \\
\hline
\end{tabular}


have the clinical picture of WG, but-ANCA and anti PR-3 antibodies were significantly elevated and a mild inflammatory syndrome was present. Eight months later, he developed specific symptoms and signs of the disease without involvement of the CNS. The imaging studies excluded any vascular or cardiac abnormality, and the patient had no objective signs of underlying arterial hypertension or a history of migraine. Therefore, we believe that his haemorrhagic stroke represented an unusual initial manifestation of WG.

WG is a primary small vessel vasculitis. Its immunological hallmark is a diffuse cytoplasmic pattern of antibodies (c-ANCA) that are usually directed against proteinase 3 (anti PR3) [13]. Concomitant testing of c-ANCA and anti PR3 antibodies can minimize false positive results [14]. In our patients both tests were consistently highly positive and normalised only after treatment. This case confirms that WG may rarely be responsible for cerebrovascular disease in young adults [8-12] and that intracerebral haematoma can exceptionally occur $[8,12]$. Moreover, it illustrates that WG may reveal itself exclusively through neurological manifestations, without typical systemic signs. In addition, though severe CNS involvement has been described in ANCA negative patients [15], it suggests that autoantibodies (c-ANCA/anti-PR3) represent a valuable marker of WG even before its clinical manifestation.

For all these reasons, we suggest that WG should be considered as a possible cause of haemorrhagic stroke in a young patient in the absence of other causes. A positive cANCA/PR-3 testing should lead to a close clinical and paraclinical follow up, in order to prevent a catastrophic outcome of this potentially serious disease.

\section{References}

1. Ruiz-Sandoval JL, Cantu C, Barinagarrementeria F (1999) Intracerebral hemorrhage in young people: analysis of risk factors, location, causes, and prognosis. Stroke 30:537-541

2. Qureshi AI, Tuhrim S, Broderick JP, Batjer HH, Hondo H, Hanley DF (2001) Spontaneous intracerebral haemorrhage. N Engl J Med 344:1450-1460

3. Bogousslavsky J, Pierre P (1992) Ischemic stroke in patients under age 45. Neurol Clin 10:113-124

4. Ferro (1988) Vasculitis of the central nervous system. J Neurol 245:766-776

5. Futrell N, Millikan C (1989) Frequency, etiology, and prevention of stroke in patients with systemic lupus erythematosus. Stroke 20:583-591

6. Sigal LH (1987) The neurologic presentation of vasculitic and rheumatologic syndromes. A review. Medicine 66:157-180

7. Rao JK, Allen NB, Pincus T (1998) Limitations of the 1990 American College of Rheumatology classification criteria in the diagnosis of vasculitis. Ann Intern Med 129:345-352

8. Nishino H, Rubino FA, DeRemee RA, Swanson JW, Parisi JE (1993) Neurological involvement in Wegener's granulomatosis: an analysis of 324 consecutive patients at the Mayo Clinic. Ann Neurol 33:4-9

9. Mandl LA, Solomon DH, Smith EL, Lew RA, Katz JN, Shmerling RH (2002) Using antineutrophil cytoplasmic antibody testing to diagnose vasculitis: can test-ordering guidelines improve diagnostic accuracy? Arch Intern Med 162:1509-1514
10. Drachman (1963) Neurological complications of Wegener Granulomatosis. Arch Neurol 8:45-55

11. Bares M, Muchova M, Dufek M, Litzmann J, Krupa P, Rektor I (2002) Wegener Granulomatosis: ischemic stroke as the first clinical manifestation (case study). J Neurol 249: 1593-1594

12. Haas JP, Metzler M, Ruder H, Waldherr R, Boswald M, Rupprecht T (2002) An unusual manifestation of Wegener's granulomatosis in a 4-year-old girl. Pediatr Neurol 27:71-74

13. Nolle B, Specks U, Ludemann J, Rohrbach MS, DeRemee RA, Gross WL (1998) Anticytoplasmic autoantibodies: their immunodiagnostic value in Wegener granulomatosis. Ann Intern Med 111:28-40

14. Schmitt WH, van der Woude FJ (2004) Clinical applications of antineutrophil cytoplasmic antibody testing. Curr Opin Rheumatol 16:9-17

15. Reinhold-Keller E, de Groot K, HollUlrich K, Arlt AC, Heller M, Feller AC, Gross WL (2001) Severe CNS manifestations as the clinical hallmark in generalized Wegener's granulomatosis consistently negative for antineutrophil cytoplasmic antibodies (ANCA). A report of 3 cases and a review of the literature. Clin Exp Rheumatol 5:541-549

Dr. C. Granziera (西) P P. Michel, MD · A. O. Rossetti, MD $\cdot$ S. Reymond, MD · J. Bogousslavsky, MD

Service de Neurologie

CHUV BH 19

1011 Lausanne, Switzerland

Tel.: + 41-21/314-1184

Fax: +41-21/314-1256

E-Mail: cristina.granziera@hospvd.ch

F. Lurati, MD

Service d'Immunologie et Allergologie Centre Hospitalier Universitaire Vaudois Lausanne, Switzerland 